Article

\title{
The Role of Smart Contracts in Sustainability: Worldwide Research Trends
}

\author{
Esther Salmerón-Manzano ${ }^{1}$ and Francisco Manzano-Agugliaro ${ }^{2, *(D)}$ \\ 1 Faculty of Law, Universidad Internacional de La Rioja (UNIR), Av. de la Paz, 137, 26006 Logroño, Spain; \\ esther.salmeron@unir.net \\ 2 Department of Engineering, ceiA3, University of Almeria, 04120 Almeria, Spain \\ * Correspondence: fmanzano@ual.es
}

Received: 7 May 2019; Accepted: 26 May 2019; Published: 30 May 2019

check for updates

\begin{abstract}
The advent and development of digital technologies has had a significant impact on the establishment of contracts. Smart contracts are designed as computer code containing instructions for executing user agreements, offering a technologically secure solution with numerous advantages and applications. However, smart contracts are not without their problems when we try to fit them into the traditional system of contract law, and their presumed benefits can become shortcomings. Bibliometric studies can help to assess the current state of science in a specific subject and support decision making and research direction. Here, this bibliometric study is used to analyze global trend research in relation to this novel contractual methodology, the smart contract, which seems to have experienced exponential growth since 2014. Specially, this analysis was focused on the main countries involved and the institutions that lead this research worldwide. On the other hand, the indexations of these works are analyzed according to major scientific areas and the keywords of all the works, to detect the subjects to which they are grouped. Community detection has been used to establish the relationship between countries researching in this area, and six clusters have been identified, around which all the work related to this topic is grouped. This work shows the temporal evolution of research related to smart contracts, highlighting that there are two trends-e-commerce and smart power grids. From the perspective of driving sustainability, smart contracts could provide a contribution in the near future.
\end{abstract}

Keywords: bibliometrics; community detection; energy; law; sustainability; smart contracts

\section{Introduction}

A contract is where individuals, groups, companies, institutions, and even governments enter into an agreement, where each of them is committed to fulfilling certain conditions. If the contract is traditional, it is written in language appropriate to the territory or legislation where the agreement is drafted, and if the parties involved agree, then they sign the document and legally agree to comply with it. All economic transactions between companies or individuals, for goods, services, or relations between the parties, are implemented by means of contracts; purchase and sale, lease, supply, loan, transport, and work are some of the most common examples. More modern examples include the contractual relationship between authors and publishers on copyright [1] and how insurance contract law differs widely between jurisdictions [2]. The performance of a contract is, ultimately, the will of the parties, and if one of them resolves not to comply with the law, it grants actions to the other signatory parties, and the appropriate judicial or arbitral process must be conducted. However, a question always arises at any time a contract is written, which is a tradeoff that must be addressed-whether or not to make a contract flexible but incomplete or rigid but comprehensive [3]. 
The digital age dominates world trade, so smart contracts can have a place in the foreseeable future. It is enough to mention that firms deploying computerized order systems are now responsible for more than $60 \%$ of the trading volume in U.S.-listed stocks [4]. The emergence of electronic and self-executing contracts is the inevitable consequence of the automation process of the Internet and the Internet of things. The legal regime integrates this contracting format without difficulty, but achieving a fully automated process implies, for example, resorting to network payment mechanisms, which are not always adapted to the current contractual type. The use of virtual currencies, such as bitcoin or electronic money, could cover this role, but the scarce or non-existent regulation of virtual currencies [5], and their dual character of unit of value and unit of account, hinder the functionality and legal security of the use of Blockchain technologies in standardized and automated contracting formats.

Blockchain technology is a distributed ledger that enables subscribers to enter and update records in the ledger, and cryptography assures that stored records will remain the same after they are added [6]. This ensures that no alterations can be made as changes would invalidate the whole register. The block network is represented by the nodes and virtual machines that are connected in peers, and each node involved has a ledger copy. The virtual machines run nodes. Once a new block has been agreed upon in the network, each node will refresh its record by appending the new block. All transactions are processed and sent from the involved nodes. All nodes in the network will agree on a consensus method for aggregating new records to the ledger [7]. As an example of a programming language, a JavaScript-like language called Solidity can provide a method for executing computer code on blockchain nodes. Computer programs that verify contracts digitally, enforce those contracts, and run on a blockchain network are called smart contracts [8].

So-called electronic contracts have been a known and enforced reality for several decades. A first question to be resolved is what is meant by a "self-executory" contract and smart contract. In our opinion, these terms allow us to approach the same reality from partially different perspectives. From a technical or informatic prism, a smart contract would be a sequence of code and data that carries out the operation in its foreseen case and does not constitute a contract in the legal sense, even though such a term appears in its name. From a legal standpoint, the term "smart contract" would refer to an existing agreement between parties for which the code sequence would be a portion or all of the same. In other words, the code itself does not constitute a contract but responds to an agreement that gives meaning to it, and that serves as its expression.

Some authors define smart contracts as self-executing digital transactions that use decentralized cryptographic mechanisms [9]. Although novel, this form of compromise is not new; it has been on the table for more than thirty years. Specifically, it was in 1994 that US computer scientist Nick Szabo proposed what was then a fanciful notion of computerized transaction protocols for intelligent contracts that executed the terms of a contract [10]. In this way, smart contracts proposed the combination of protocols with user interfaces to formalize and secure relationships across computer networks [11]. Recently, the development of the Blockchain and Bitcoin technologies has once again driven the approach to the potential of smart contracts [12]. In Figure 1, the process of creating a smart contract and the blockchain is represented in a schematic form.

Smart contracts are not like commonly understood contracts, particularly for legal scholars and practitioners. The difference, however, is that because these contracts are intelligent, they can be fulfilled automatically. Even if these contracts are fulfilled automatically, it is necessary for each of the members to do their part. The main differences between smart and traditional contracts are the ways they are written, their legal implications, and how the agreed conditions will be fulfilled. These distinctive characteristics are the ones that provide the advantages and disadvantages of both types of contracts, which are easily observable when understanding how they work.

However, there is a long history of self-executory contracts. Take the example of 'on demand' guarantees. While clearly contracts, on demand guarantees do not reflect any particularly general idea of what a contract is, but rather a highly specialized institutional context where, firstly, it is possible to codify a transaction so that self-executing rights have practical meaning and, secondly, there is a 
highly specific, narrow context of use, where the multiplicities generally implicit in a contract can be controlled.
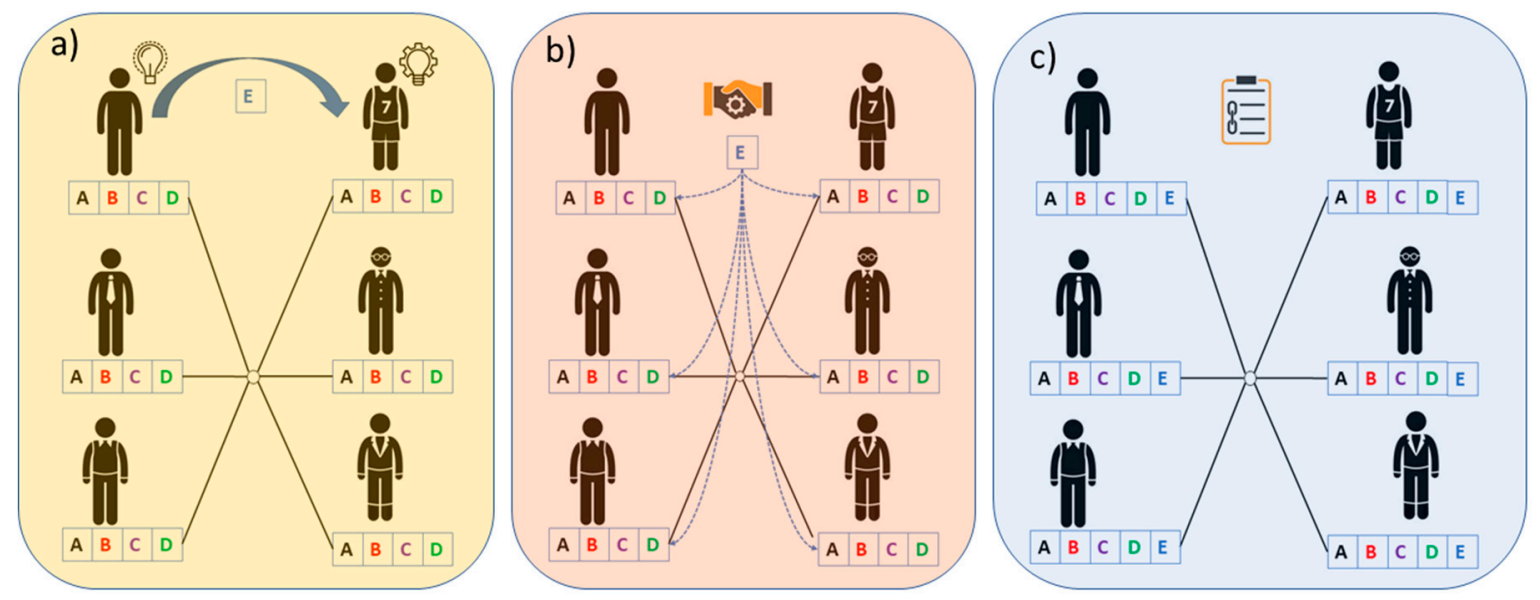

Figure 1. Smart contracts: (a) transaction idea, (b) smart contracts and blockchains, (c) transaction confirmed and added as a block to the blockchain.

A novel area of law is emerging around blockchain platforms and automated transactions [10]. The so-called Internet of Things (IoT) refers to a connection to the web for millions of devices. In IoT, fridges, washing machines, televisions, and vehicles can connect to the Internet and exchange data with the millions of other users or computers on the web. In this scenario, which is predicted for the near future, smart contracts could go beyond single-tract contracts and ensure the execution of successive-tract contracts. However, some authors, specialized in law, advise on the emerging risks in the use of smart contracts, which could certainly be a branch of research in this field [13].

Blockchain systems can be beneficial for non-centrally controlled storage, notarizing, and subsequent execution of intelligent contracts. However, fundamental problems can arise about the modification and termination of intelligent contracts. To simplify the modification of intelligent blockchain contracts, declarative language could be used, but compared to its imperative counterparts, it may not live up to expectations in terms of computational complexity and associated costs. For these reasons, we must emphasize that imperative and declarative approaches are not incompatible, but instead have the potential to complement each other, which can lead to interesting theoretical and practical opportunities [14].

However, "failed" smart contracts already exist. These contracts have even classified into prodigal, suicide, and greedy contracts [15]. Prodigal contracts are those which have fallen into the hands of hackers, thereby changing the direction the Ethers should go in this case. This fraud has caused crypto-currencies to reach a fraudulent address and become the property of the fraudster who had been placed between the contracting party and the actual recipient of the crypto-currency [16]. Suicide contracts are those that are closed when an exit requirement is activated by the person carrying out the attack. It may be that there is a wrongly implemented exit clause, as has already happened, and the consequence is quick to occur. Under the cover of a legal act, the wrong person ends up taking all the encrypted money that the smart contract entails [17]. It should also be noted that inadequate protection of the information in one of these contracts also ends up allowing funds to be moved to illegitimate places. Greedy contracts may be due to bad practice or miswriting, but the fact is that the contracting party will no longer have the legitimacy to receive its encrypted currency. It gets out of their control, and ends the contract. This is an example of economic loss due to vulnerability failure [18].

From a sustainability point of view, it is possible to find many works that show the potential of smart contracts [19]. Nikolakis et al. [20] studied how law, regulation, and private standards have evolved to enhance sustainability in value chains. As an example, they show how blockchains can improve sustainability by informing consumers about the origin of products, provide guarantees 
about the authenticity of information, and offer a mechanism for enforcing representations through the smart contract function of the blockchain. Park et al. [21] propose the implementation of an energy transaction platform based on P2P (peer-to-peer) blockchains to support energy efficient transactions between prosumers, which will encourage a more sustainable trading ecosystem between consumers and prosumers. Giungato et al. [22] propose the development of an Energy Internet, based on a new type of power grid structure based on the generation of renewable energy, distributed energy store devices, and the existent of the Internet [23]. Gatteschi et al. [9] propose a use for the insurance sector and give the example of $\mathrm{B} 3 \mathrm{i}$, the first blockchain-centered insurance consortium [24].

Other characteristics of smart contracts to expand their potential for sustainability are to accelerate and automate the exchange of information on the value of natural resources and environmental sustainability. Examples of sustainable supply chain traceability can be found as agrifood products [25], as forests (if the trees are cut without destroying natural forests) [26], or as payment for ecosystem services [26]. Another great smart contract approach is the application to improve logistics services and supply chains, such as in the pharmaceutical sector [27] or alimentary supply chain [28].

On the other hand, there are studies that warn about the problems of these technologies. For example, the advantages of blockchain technology can be overshadowed by the intentionally resource intensive nature of their transaction verification process, which now menaces the climate on which we depend to survive [17]. There is previous research that has studied the relationship of sustainability with "bitcoin", "digital currency", "cryptocurrency", and "virtual currency" [29], or the relationship of sustainability with the "Energy Internet" [30]. From a legal point of view, smart contracts, in contrast to traditional contracts, should address issues such as trial risks, enforcement risks, and jurisdictional risks. In fact, it would be useful to analyze the on-demand guarantee example to see in what kinds of institutional contexts they might be used. In this regard it is possible to find, as an example, contracts for insurance. Insurance contracts, or more specifically reimbursement in specific, narrowly defined loss scenarios, much more clearly provide a similar highly specialized institutional context comparable to the existing generally used self-executory contracts, such as on demand guarantees.

In short, this new technology has its advantages and disadvantages. Therefore, as it is a technology under development, work is continuing to optimize its operation to the maximum. On the other hand, there are investigations that alert to the problems of these technologies. For example, the advantages of blockchain technology can be overshadowed by the intentionally resource intensive nature of their transaction verification process, which now menaces the climate on which we depend to survive [31]. Until now, no systematic study of all published works related to smart contracts has been carried out. A bibliometric analysis is a useful tool, both for the study of the state of different scientific disciplines and for the scientific production of a given region, discipline, or topic. Its study aim is to physically represent the products of thought in documents. In other words, intellectual knowledge supported by material support-the publications.

Bibliometric analyses can determine which fields of research have been carried out, and which organisms and countries are the main ones applicable in researching this topic. Bibliometrics and the use of their indicators are necessary scientific tools because they allow the quantification of science in an objective way, as they show the current knowledge in a given scientific field and its compilation in bibliographic databases. The importance of bibliometric studies is carried out in all branches of science, such environment [32] and education [33]. In this context, the present work has the main objective of analyzing the global research trends on smart contracts, with special attention to analyzing the main areas in which efforts are being made by the scientific community.

\section{Methods}

One of the world's largest databases of scientific literature is Elsevier's Scopus, which contains approximately 18,000 titles from more than 5000 international publishers, including coverage of 16,500 peer-reviewed journals in the areas of Science, Technology, Medicine, and Social Sciences, including the 
arts and humanities. This is the methodological basis of this study, which has been used successfully in other bibliometric studies [34].

The coexistence of two large scientific databases, Scopus and Web of Science (WoS), raises the question of the stability of the statistics obtained by one or the other sources of information. Several studies have measured the overlap between databases and the impact of using different data sources for specific research fields on bibliometric indicators, demonstrating a larger number of journals indexed by Scopus compared to WoS [35]. Regarding the overlap, $84 \%$ of the WoS titles are also indexed in Scopus, while only $54 \%$ of the Scopus titles are indexed in WoS [36]. For example, some studies related to citations in the papers conclude that each database covered $90 \%$ of the citations in the other database when the citation period is limited to Scopus citation coverage for 1996 and beyond [37].

The methodology followed in this work is described in Figure 2. The search term is first consulted in the Scopus database (1). The term smart contract was used for the entire historical series up to 2018, where the exact search query was TITLE-ABS-KEY (smart AND contract). The resultant search is exported to Comma Separated Value (CSV) text format (2) for each of the fields studied (i.e., publications by year, type of publication, publications by category indexed by Scopus, publications by country, publications by institutions, and keywords and their frequency). Thirdly (3), the previously downloaded text files are imported into Excel, and all of them are represented without removing any data. Fourthly (4), the keywords are represented by means of the free online software Word Art (https://wordart.com/) to obtain a cloud words where the most important ones are highlighted. Fifth (5), the methodology was developed to analyze the scientific communities or clusters associated with this thematic. The exported information of the complete search was imported in csv format in the free and online bibliometric analysis software called VOSviewer (http://www.vosviewer.com/). Here, the relations between the countries, interpreted through the co-authors of every one of the works, were analyzed, and the research clusters of the works were analyzed, using the relations between all keywords of all the works.

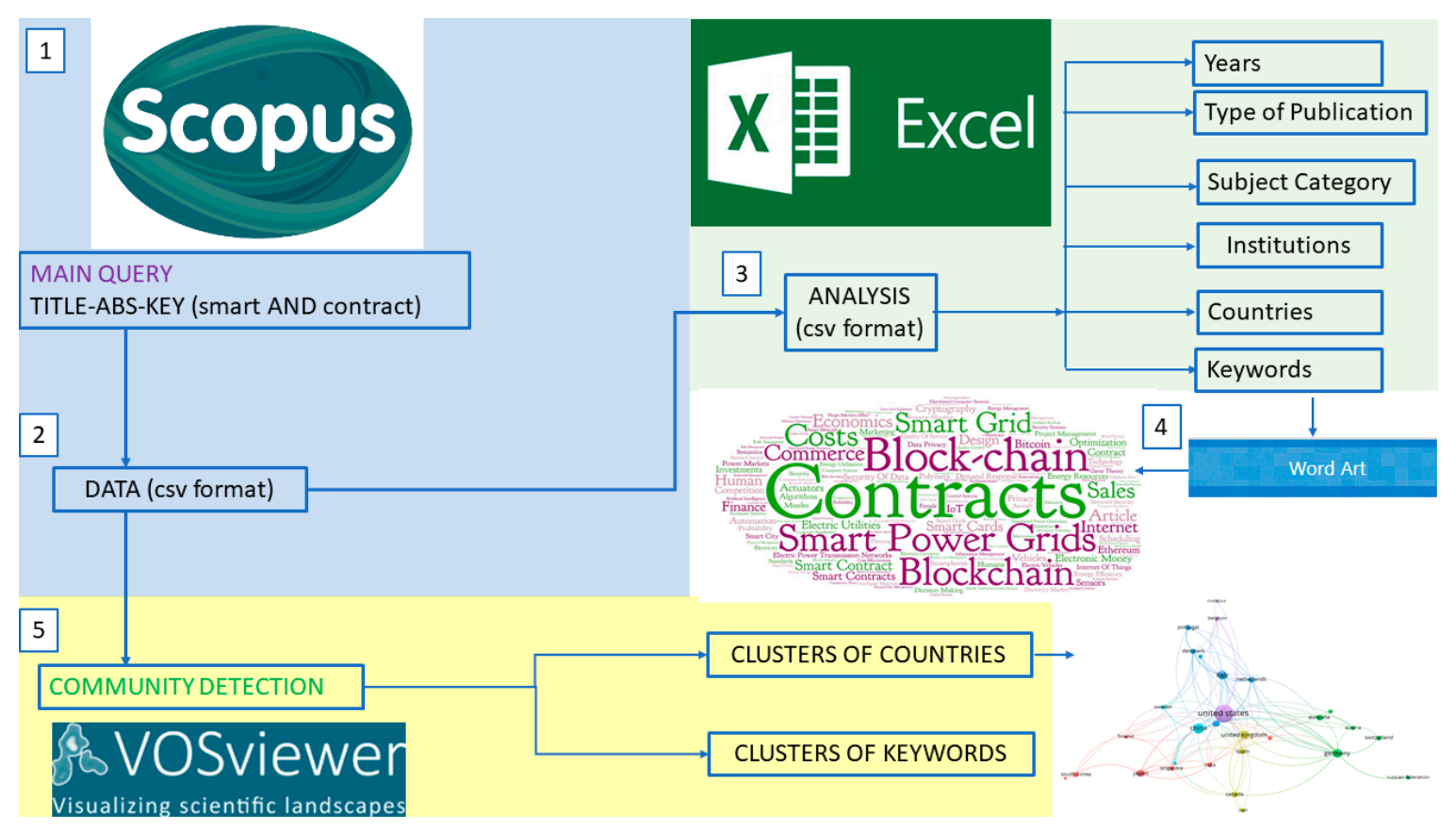

Figure 2. Methodology chart.

With respect to the chosen software, it should be noted that for the direct representation of results, bar charts, percentage distribution, or lines of evolution over time, a spreadsheet has been used via Microsoft Excel, which allows the direct import of the csv format exported by the Scopus database. For the clouds of words, the Word Art software has been chosen because it is free and online and 
allows the import of data from excel. Finally, the community detection software, we also opted for free software available online that allows the direct import of data in csv format exported from Scopus.

Finally, the community detection software used was the VOSviewer, which was also chosen for being free software available online that allows the direct import of data in the csv format exported from Scopus and also allows the figures to be exported to a large range of graphical formats. The VOSviewer delivers three displays: Network visualization as clusters, overlay visualization as temporal evolution, and density visualization. In all cases, the parameters chosen for the analysis were: normalization method (association strength), layout (attraction 2, repulsion 0), clustering (resolution 1.00, minimum cluster size 1), and rotate (90 degrees).

\section{Results and Discussion}

\subsection{Evolution of Scientific Production, Languages, and Types of Documents}

The search yielded just over 1700 documents up to the year 2018, the evolution of which is reflected in Figure 3. This result shows that the first works published date back to the 1980s, but it was not until 2003 that they began to reach a certain relevance, with the volume of publications stabilizing at 50 works per year. However, the most remarkable increase can be seen from 2014 onwards, at which point the upward trend can be considered exponential.

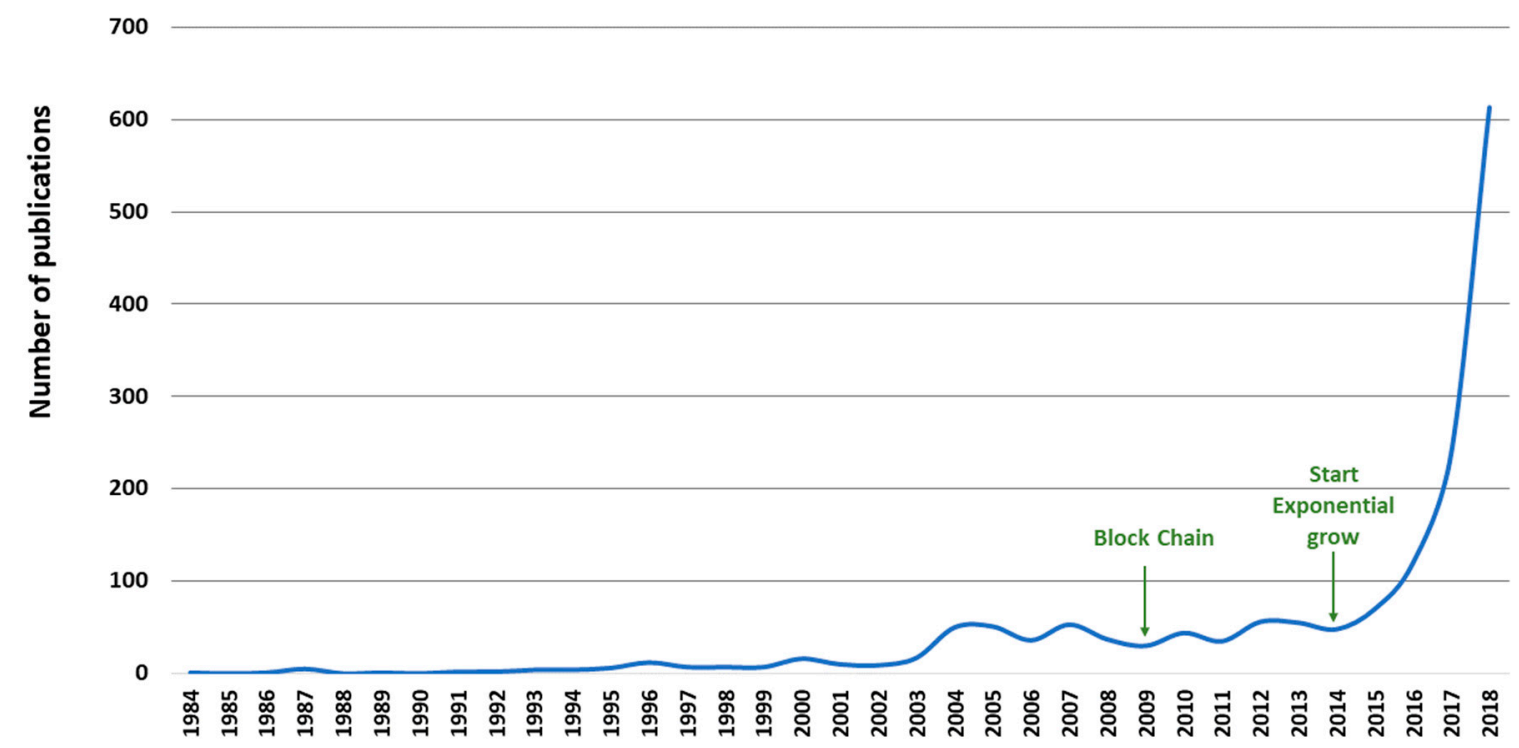

Figure 3. Evolution of scientific publications related to smart contracts.

If the results are analyzed according to the type of publication (Figure 4), it is observed that most results are communications presented at congresses $(53 \% ; 46 \%$ conference papers and $7 \%$ conference reviews), followed by articles in journals (38\%; $33 \%$ articles and $5 \%$ reviews), as well as books and book chapters $(2 \%)$. The rest is distributed among other formats such as editorials, notes, and letters. The high percentage of conferences in relative terms is because it is a very recent technology or area of interest. Thus, when the subject matter of research is consolidated, the percentage of books is higher and, above all, the number of articles in relation to number of congresses is higher. Note that scientific conferences are usually on very specific scientific topics and are aimed at sharing ideas among researchers. In short, these scientific events are key activities for the process of knowledge dissemination, for the presentation of new findings, and for the development of science in a community. 


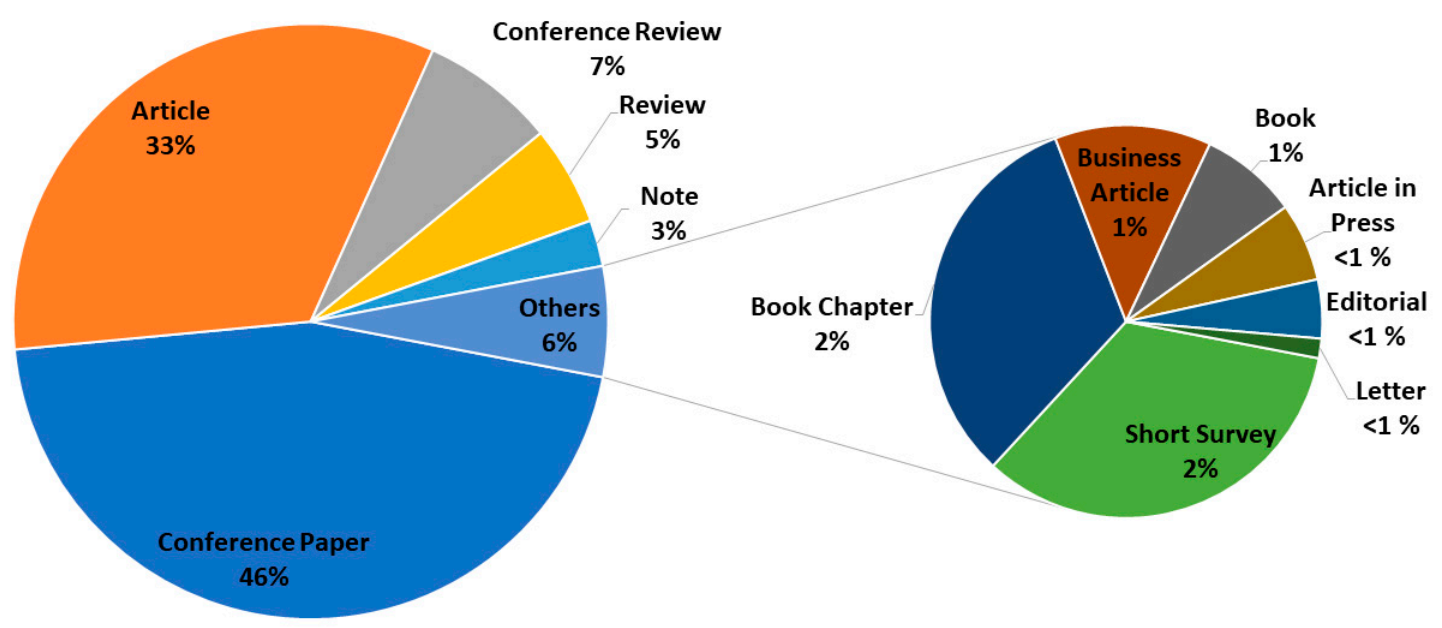

Figure 4. Distribution of publication type in relation to smart contracts.

These papers are written mostly in English, accounting for more than $97 \%$ of publications, as is usual when consulting international scientific databases. However, there are also works published in Chinese, French, Russian, German, Dutch, Portuguese, Spanish, and Japanese.

\subsection{Distribution of Publications by Institution and Country}

Regarding the countries which have carried out the most research on this subject, the USA stands out, with more than $22 \%$ of the total number of published papers, followed by China, with more than $6 \%$, and finally the United Kingdom, Germany, and Italy, with slightly more than 5\%.

The affiliations of the works do not essentially respond to the same order as the countries. Thus, it was shown that the ten institutions that have published the most papers are, in order, Danmarks Tekniske Universitet, Universita degli Studi di Trento, National University of Singapore, Tallinn University of Technology, Cornell University, Instituto Politecnico do Porto, Delft University of Technology, UC Berkeley, University of Electronic Science and Technology of China, and Tsinghua University. It can be seen that two are from the USA and two are from China. Table 1 lists the main institutions and their main keywords used.

Figure 5 shows the relationship between research in this area in different countries using the VOSviewer software. In the network visualization of Figure 5, countries are represented by a circle. The size of the label and the circle of an item is determined by the weight of the country. The higher the weight of a country, the larger the circle and the label of the country. These clusters or communities are shown in Table 2. There are six communities of scientific collaboration where, in principle, the apparent lack of affinity between countries is striking, except in the case of community 3 , which corresponds to all European countries. The cluster name is selected by the country that has the greatest weight within the cluster. Figure 5 shows the great centrality of the USA in this area, and although they belong to other clusters, China and the UK also occupy important positions of centrality. The clusters are led by Japan, Germany, Italy, UK, USA, and China, which, as can be seen, are the most industrialized countries in the world, all of them belonging to the G8 countries except China. For example, in the case of United Kingdom, the relationship is concentrated mainly with Canada, Iran, and Spain. 
Table 1. Main institutions and their keywords.

\begin{tabular}{|c|c|c|c|}
\hline Institution & 1 & 2 & 3 \\
\hline Danmarks Tekniske Universitet & Smart Power Grids & Energy Resources & Distributed Energy Resources \\
\hline Universita degli Studi di Trento & Smart Cards & JAVA Card & Multiapplication Smart Cards \\
\hline National University of Singapore & Electronic Money & Chromium Compounds & Cryptography \\
\hline Cornell University & Cryptography & Electronic Money & Ethereum \\
\hline Instituto Politecnico do Porto & Energy Resources & Smart Power Grids & Distributed Energy Resources \\
\hline Delft University of Technology & Aggressive Environment & Anode Material & Cathodic Protection \\
\hline UC Berkeley & Commerce & Smart Grid & Electricity Market \\
\hline University of Electronic Science and Technology of China & Blockchain & Big Data & Commerce \\
\hline Tsinghua University & Blockchain & Bitcoin & Business Modelling \\
\hline
\end{tabular}

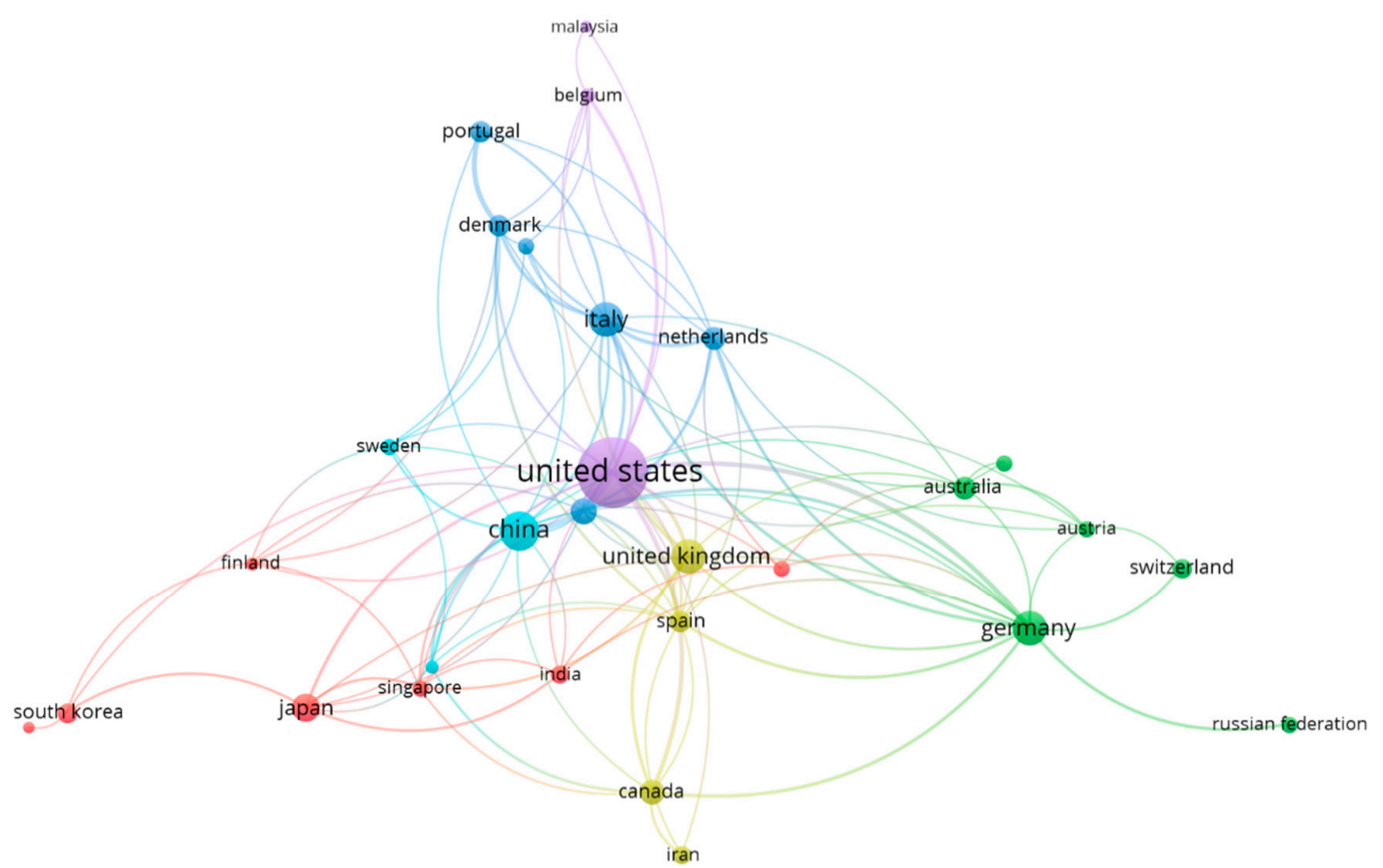

Figure 5. Relationship between countries publishing on smart contracts. 
Table 2. The detected clusters of countries related to research on smart contracts.

\begin{tabular}{cccc}
\hline Cluster & $\begin{array}{c}\text { Color } \\
\text { (Figure 5) }\end{array}$ & Main Countries & $\begin{array}{c}\text { Main Country } \\
\text { of Publications) }\end{array}$ \\
\hline 1 & Red & Japan, Singapore, South Korea, Finland, India & Japan \\
2 & Green & Australia, Austria, Germany, Russia, Switzerland & Germany \\
3 & Blue & Denmark, Italy, Netherlands, Norway, Portugal & Italy \\
4 & Yellow & Canada, Iran, Spain, UK & UK \\
5 & Purple & Belgium, Malaysia, USA & USA \\
6 & Cyan & China, Hong Kong, Sweden & China \\
\hline
\end{tabular}

\subsection{Main Areas of Knowledge and Keyword Analysis}

The analysis of the keywords with which the works are indexed is one of the most relevant aspects in bibliometric analysis [38,39]. If the results obtained are analyzed according to keywords, and a cloud word is made with on-line software (see Figure 6) a strong relationship can be observed between blockchain technology, smart grids (SGs), and smart energy grids, as well as virtual currencies or electronic money (Ethereum, Electronic Money). It is worth highlighting the main areas of knowledge in which research is being carried out.

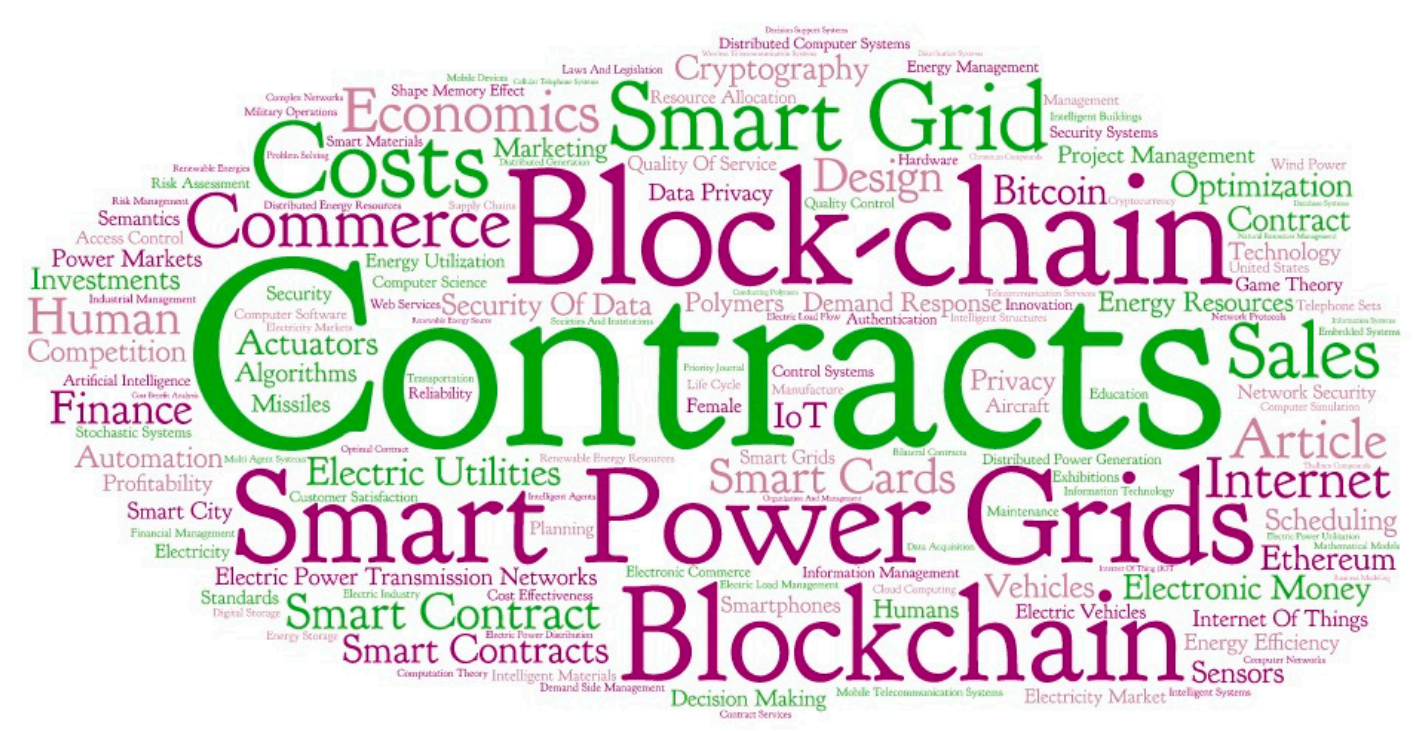

Figure 6. the cloud of keywords used in the work on smart contracts.

Figure 7 groups the keywords by large areas of knowledge, according to the Scopus indexation (subject area), and it can be seen that the first one, as was foreseeable, is computer science, followed by engineering via the theme of intelligent networks. The following areas of knowledge are those of energy and, later, of social sciences, among which the studies in law are framed. Indeed, if one looks at the keywords most commonly used in each country's publications (Table 3) one can see that blockchain and smart grid dominate in almost all the major countries with scientific publications on this subject.

There are also two keywords that, a priori, could go unnoticed, commerce and smart cards, which have a great relationship with the categories of social sciences and business, management, and accounting. This is particularly evident in the analysis of smart contracts in their focus on brokering, their transparent nature, the promise of greater commercial efficiency, lower legal and transaction costs, and, above all, the apparent advantage of anonymous transactions [40]. 


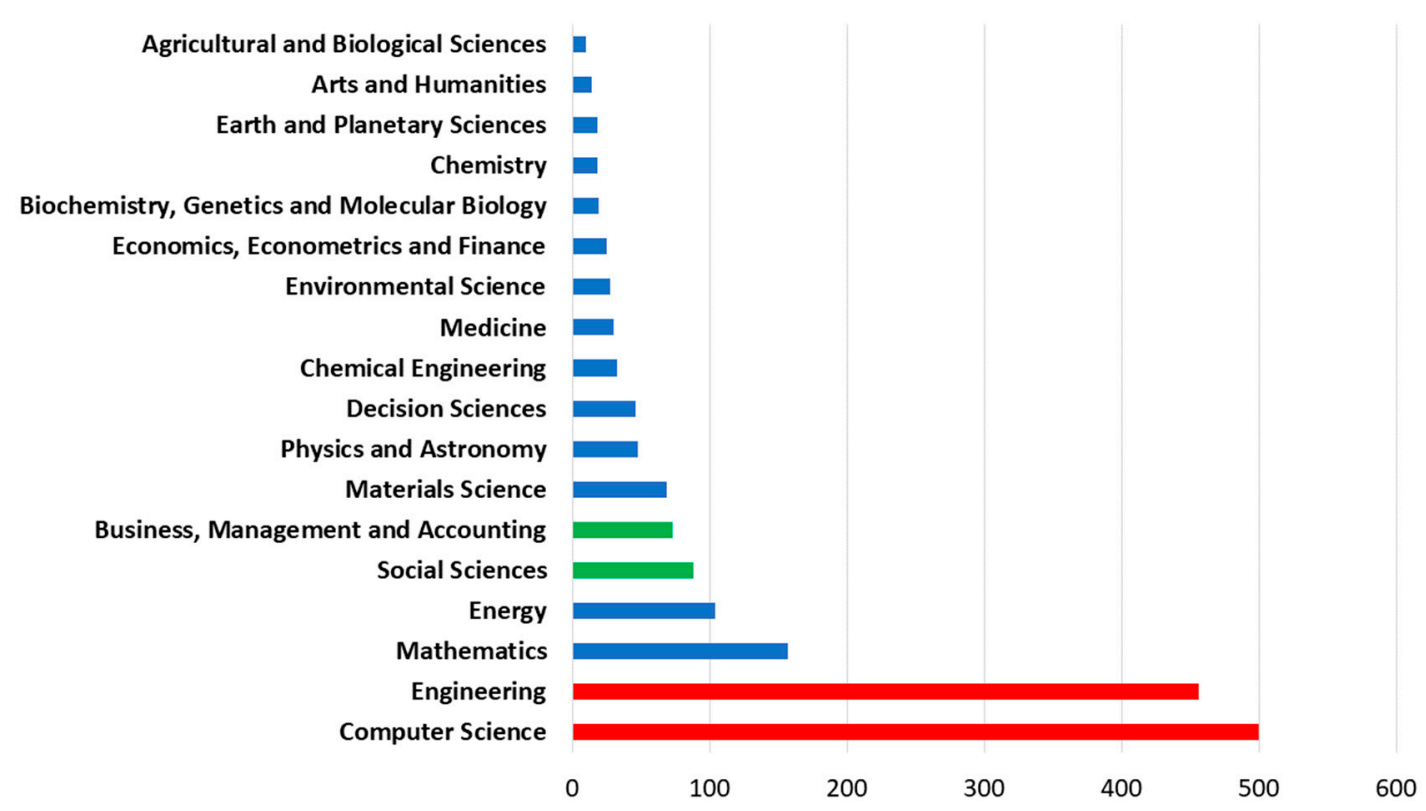

Figure 7. Thematic distribution of works related to smart contracts.

Table 3. Countries and their three main keywords related to smart contract.

\begin{tabular}{cccccc}
\hline Country & $\mathbf{N}$ & $\mathbf{\%}$ & $\mathbf{1}^{\mathbf{o}}$ & $\mathbf{2}^{\mathbf{o}}$ & $\mathbf{3}^{\mathbf{0}}$ \\
\hline United States & 228 & 22.03 & Blockchain & Smart Grid/ Smart Power Grids & Electronic Money \\
China & 70 & 6.76 & Blockchain & Smart Power Grids & Commerce \\
United Kingdom & 61 & 5.89 & Electronic Money & Blockchain & Blockchain \\
Germany & 55 & 5.31 & Smart Power Grids & Electric Power Transmission Networks & Commerce \\
Italy & 55 & 5.31 & Blockchain & Smart Cards & Profitability/ Smart Grid \\
Japan & 36 & 3.48 & Smart Power Grids & Commerce & Smart Cards \\
France & 33 & 3.19 & Automation & Costs/ Economics & Smart Power Grids \\
Canada & 29 & 2.80 & Blockchain & Electric Power Transmission Networks & Distributed Energy Resources \\
Netherlands & 26 & 2.51 & Commerce & Blockchain & Telephone Sets \\
Australia & 23 & 2.22 & Blockchain & Smart Grid \\
Portugal & 23 & 2.22 & Smart Power Grids & Energy Resources & Energy Resources \\
Spain & 22 & 2.13 & Smart Power Grids & Distributed Energy Resource & Energy Resources \\
Denmark & 20 & 1.93 & Smart Power Grids & Electric Power Transmission Networks & Smart Power Grids \\
Switzerland & 18 & 1.74 & Blockchain & Demand Response & Internet of Things \\
South Korea & 17 & 1.64 & Smart Power Grids & Computer Science & Distributed Computer Systems \\
India & 16 & 1.55 & Computation Theory & Decision Making & Costs \\
Iran & 16 & 1.55 & Smart Power Grids & Commerce & \\
\hline
\end{tabular}

\subsection{Community Detection: Analysis of the Interconnection Between Keywords}

Considering a community as a system composed of multiple interdependent elements, with a very wide range of relationships and intensities that are highly variable and dependent on each other, we could accept, conceptually, that communities are made up of a highly cohesive central core and peripheral spheres with unions increasingly weaker compared to the center. The central core would be structured by the most significant elements of the community, in terms of granting a definable individuality, representing the links between its constituents, and the strongest and most significant elements within the entire community complex. Communities or clusters are usually groups that are more likely to relate to each other than to members of other groups. When this analysis was completed by collaboration between authors from different countries using what is known as community detection, Figure 8 was obtained. An available online application, called VosViewer, which was developed specifically for this type of analysis of scientific production, was used for this purpose [41].

Clusters, or communities in networks, are one of the most notorious aspects of leading bibliometric studies [42]. These communities are groups that are more likely to be interconnected with each other than with members of other groups [43]. By analyzing the keywords of all the works published on smart contracts with the application calibrated for community detection, Figure 8 was obtained, in which six clearly differentiated communities have been detected (Table 4). 


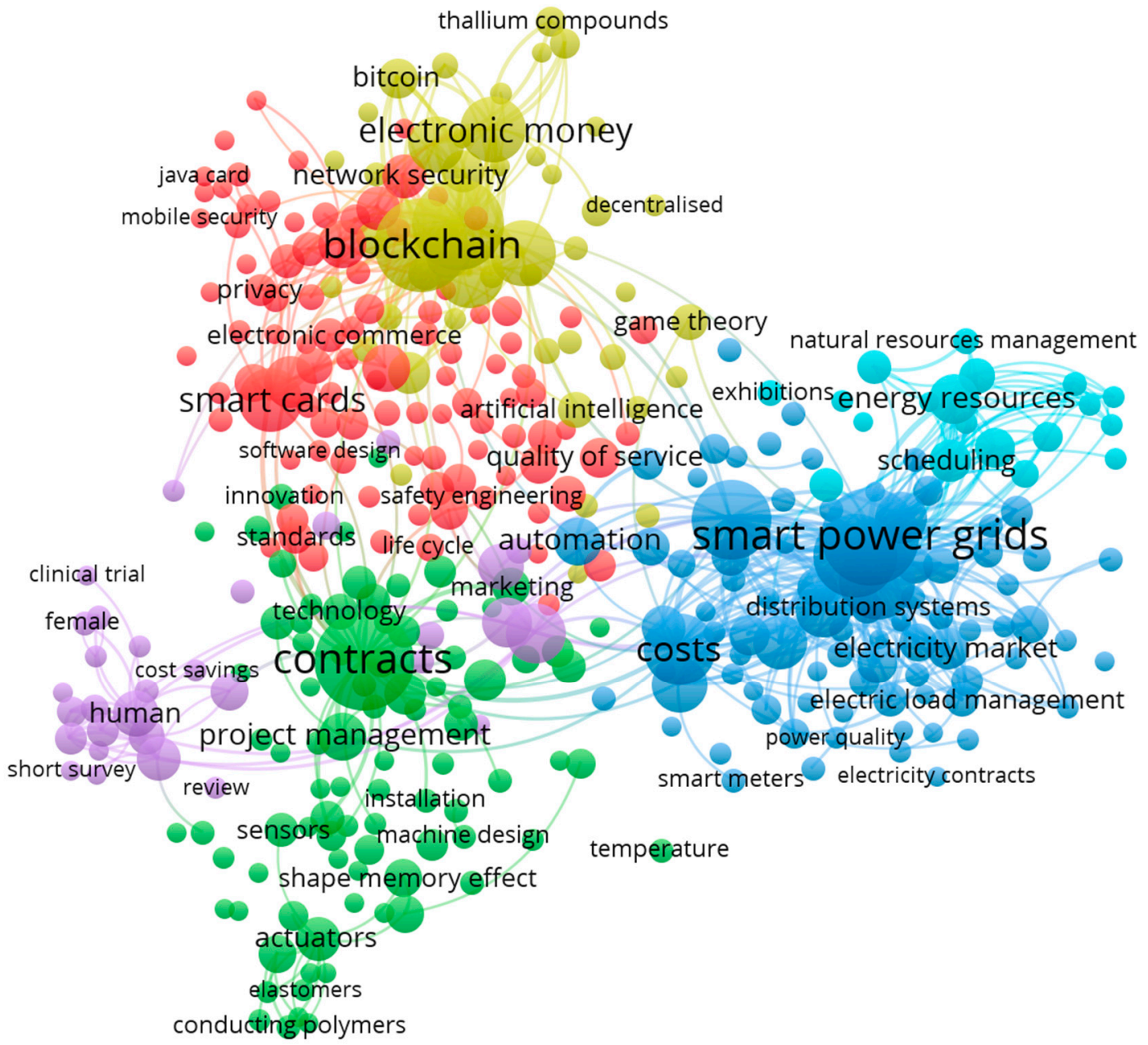

Figure 8. The relationship between keywords in the smart contract works.

Table 4. Detected clusters of keywords related to research on smart contracts.

\begin{tabular}{cllll}
\hline Cluster & $\begin{array}{c}\text { Color } \\
\text { (Figure } 8)\end{array}$ & \multicolumn{1}{c}{ Keywords } & Cluster Name & \% \\
\hline 1 & Red & $\begin{array}{l}\text { Smart cards, security data, smart phone, internet, } \\
\text { authentication, network security, internet of things, } \\
\text { laws and legislation }\end{array}$ & Smart cards & 26.9 \\
\hline 2 & Green & $\begin{array}{l}\text { Contracts, computer software, project managements, } \\
\text { marketing, societies and institutions }\end{array}$ & Contracts & 23.6 \\
\hline 3 & Blue & $\begin{array}{l}\text { Smart power grids, electric power transmission } \\
\text { network, commerce, electric load management, costs }\end{array}$ & Smart power grids & 23.3 \\
\hline 4 & Yellow & $\begin{array}{l}\text { Blockchain, bitcoin, electronic money, } \\
\text { smart contracts, cryptography }\end{array}$ & Blockchain & 12.5 \\
\hline 5 & Purple & $\begin{array}{l}\text { Economics, human, organization and management, } \\
\text { decision making }\end{array}$ & Economics & 8.5 \\
\hline 6 & Cian & $\begin{array}{l}\text { Energy resources, distributed energy resources, virtual } \\
\text { power players, natural resources managements }\end{array}$ & Energy & 5.2 \\
\hline
\end{tabular}

The largest volume is cluster 1 (red), which groups $26.9 \%$ of keywords. The main keyword is smart cards, which has the highest density relationship with authentication and internet within its cluster, as well as cryptography (cluster 4 ) and contract (cluster 2). The first works related to smart cards from 1998 are mainly for use in electronic commerce [44]. 
Cluster 2 (green), which groups $23.6 \%$ of keywords, is focused on contracts. Its clusters highlight its relationship with laws and legislation and trade (marketing, purchasing, or project management). The relationship with other clusters is mainly through economics (cluster 5), cost or sales (3), smart cards (cluster 1), and blockchain (cluster 4).

Cluster 3 (blue) is focused on smart power grids. In general, one could say that this cluster is fairly independent, since its main relationships are within its own cluster. Thus, its main relationships are with electric power transmission networks, electric utilities, electricity market, commerce, electric load, energy management, and wind power. With other clusters, its main links are through blockchain and game theory (cluster 4), economics (cluster 3), and energy resources (cluster 6).

Cluster 4 (yellow) is mainly grouped around blockchain, which has the highest density relationship with electronic money and bitcoin within its cluster. Blockchain is focused on programming and cryptocurrency, such as Bitcoin. This is because cryptocurrencies and smart contracts are based on the same technology (blockchain) [8]. Regarding the relationship with other clusters, we find a connection mainly with commerce (cluster 3), economics (cluster 5), and security data (cluster 1).

Cluster 5 is grouped around economics, human, organization and management, or decision making. The importance of this cluster is that although it is not particularly important in terms of weight ( $8.5 \%$ of keywords), it is centered on the network, which shows that it is a link-point for all this research. This result possibly suggests that, in the near future, smart contract applications will play an important role in the different domains of modern organizations [45]. The other clusters highlight their relationship with blockchain (cluster 4), contracts (cluster 2), and smart power grids (cluster 3). Within its cluster, the main relationship is with terms based on the social economy, where key words such as human, male, female, adult, investment, transparency, and decision-making stand out.

Based on the previous study of clustering of keywords by clusters, its temporal evolution can be analyzed (Figure 9). It can be seen how clustering has temporarily evolved since smart cards and contracts to mainly two lines-first, to electronic commerce or quality of service, and second, to costs; from the first line (electronic commerce) to blockchain or network security and electronic money, and from the second line to cost energy issues, mainly regarding smart power grids. This gives an idea about the transition of the worldwide research in this topic.

There is no doubt that, despite the objections that can and must be made, bibliometric studies facilitate the understanding of research activity in a given scientific field. In this research, it has been observed from the analysis of keywords and the scientific communities that support them, that there is not yet a community that dedicates itself to legislation and laws, despite being an essential aspect of the subject in which it is concerned. However, it should be noted that bibliometric analyses are generally valid in those areas in which scientific publications are an essential result of research. For this reason, the validity of bibliometric analyses is of maximum relevance to the study of basic areas, where scientific publications predominate, to a lesser extent in technological or applied areas, and to a much lesser extent in the areas of social and legislation. Therefore, comparisons between thematic areas and within these, scientific communities, should be made with caution, because the publication habits and productivity of authors differ according to knowledge areas. This is the case of this study, where differences were found between the areas of social sciences or business, management and accounting, and those of computer science or engineering.

In the absence of a greater degree of maturity and extension of use, smart contracts raise several issues from a legal standpoint. Our law does not contemplate them, nor do judicial precedents yet exist to help in this regard. However, it must be made clear that general contract law does provide criteria for verifying whether a smart contract can be legally valid and enforceable. The legal systems of our environment recognize the autonomy of the parties to freely reach legally enforceable agreements and contracts in the terms they consider, provided that the basic requirements of contract law are met, both in content (being a legal object and not a contravention of mandatory legal rules, ensuring the existence of valid consent of the parties, and obeying a legal cause) and in the manner of formalizing them. 


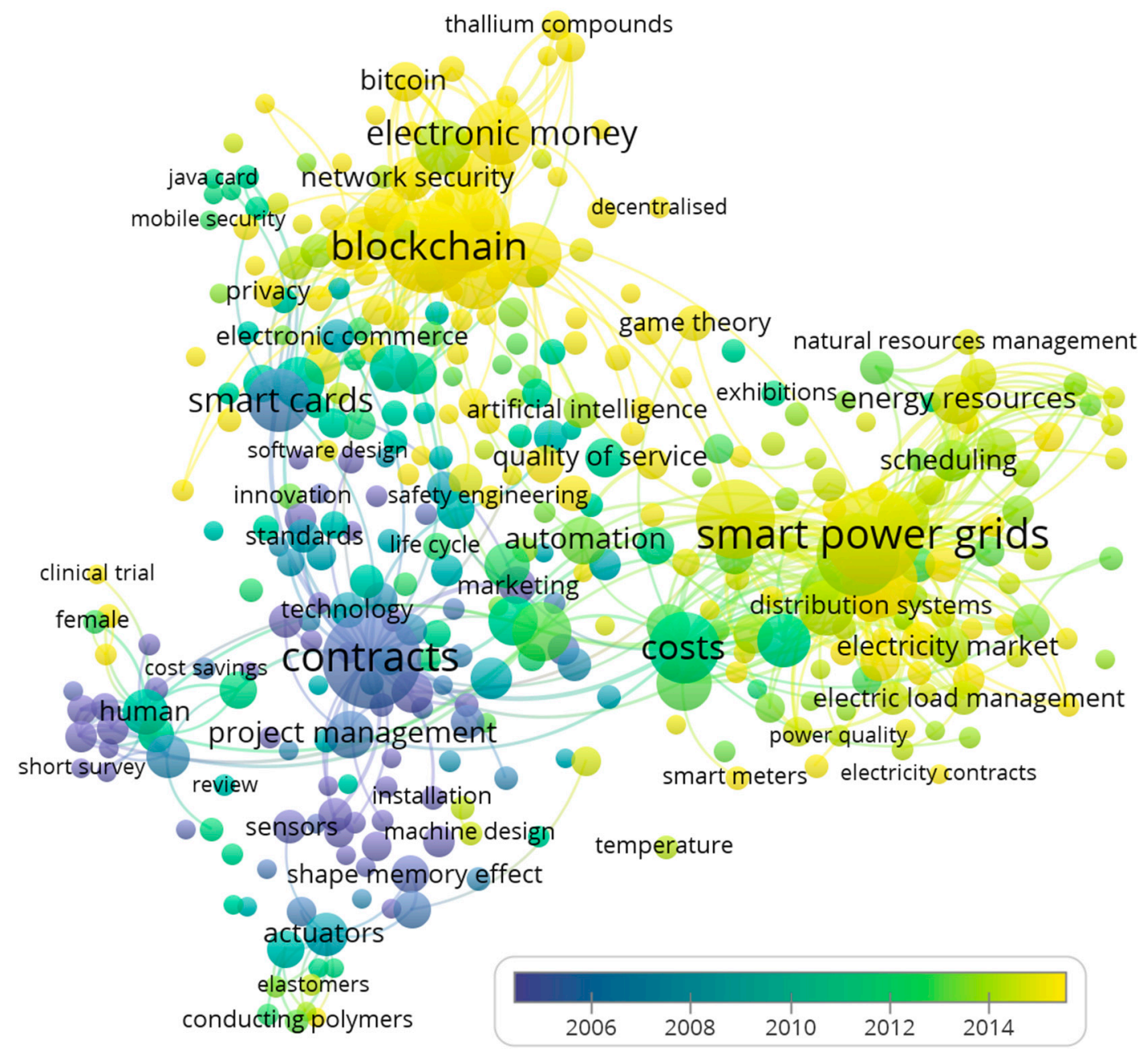

Figure 9. The relationship between keywords in smart contract works and its evolution.

\section{Conclusions}

This paper has analyzed the main trends in global research on intelligent contracts, highlighting the main countries that have made a scientific effort in this area, in order of importance- the USA, China, the United Kingdom, Germany, and Italy—and scientific collaboration between these countries does not necessarily respond to obvious or expected trade relations. For example, in the case of Spain, the relationship is concentrated mainly with Canada, Iran and the United Kingdom. The publication of research, mainly in the form of communications in congresses, shows that intelligent contracts are emerging technologies and still in the initial study phase, unlike other more established technologies that do the same work in the form of articles or even books. In order of importance, the main subject areas found were computer science, engineering, mathematics, energy, social sciences, business, management, and accounting. In the absence of a greater degree of maturity and widespread use, smart contracts raise several legal issues that need to be addressed. Consequently, this paper demonstrates that the Social and Legal Sciences occupy the fifth position in the number of published papers, clearly indicating that the technological aspect of this issue needs to be given a legal character, as its implications and scope are of the utmost interest for the international scientific community. Therefore, further legal progress must be made on the reality of this new form of contracts, especially to support the two main lines towards which they have evolved-electronic money and energy costs.

Finally, the analysis of the themes of all these works, by means of the analysis of the keywords, have shown that there are 6 clearly differentiated clusters around which all these works can be grouped. Their temporal evolution shows a tendency towards two main lines of research-the electronic money 
(cryptocurrencies, or bitcoins) and the smart power grids and electricity market (electricity consumption, electric industry). Given the growing scientific interest shown by the growing number of publications, smart contracts can overcome the problems pointed out by many detractors, and they could be a driver of sustainability. For environmental sustainability applications, smart contracts should pay particular attention to small communities, since it has been observed that small communities are still poorly covered by this particular technology, in spite of often being stewards of natural resources.

Author Contributions: E.S.-M. and F.M.-A. have contributed in the same way to the writing of this manuscript, both authors have read and approved the final manuscript.

Funding: This research received no external funding.

Acknowledgments: The authors of this manuscript wish to thank the CIAIMBITAL research center for its support of this research.

Conflicts of Interest: The authors declare no conflict of interest.

\section{References}

1. Bagheri, P.; Hassan, K.H. Access to information and rights of withdrawal in internet contracts in Iran: The legal challenges. Comput. Law Secur. Rev. 2015, 31, 90-98. [CrossRef]

2. Jackson, H.E. Variation in the intensity of financial regulation: Preliminary evidence and potential implications. Yale J. Regul. 2007, 24, 253.

3. Burden, K. "Cloud bursts": Emerging trends in contracting for Cloud services. Comput. Law Secur. Rev. 2014, 30, 196-198. [CrossRef]

4. Diamond, S.F.; Kuan, J.W. Are the stock markets "rigged"? An empirical analysis of regulatory change. Int. Rev. Law Econ. 2018, 55, 33-40.

5. Salmerón, E. Necesaria regulación legal del Bitcoin en España. Rev. De Derecho Civ. 2017, 4, $293-297$.

6. Kuo, T.T.; Kim, H.E.; Ohno-Machado, L. Blockchain distributed ledger technologies for biomedical and health care applications. J. Am. Med. Inform. Assoc. 2017, 24, 1211-1220. [CrossRef]

7. Zheng, Z.; Xie, S.; Dai, H.N.; Chen, X.; Wang, H. Blockchain challenges and opportunities: A survey. Int. J. Web Grid Serv. 2018, 14, 352-375. [CrossRef]

8. Christidis, K.; Devetsikiotis, M. Blockchains and smart contracts for the internet of things. IEEE Access 2016, 4, 2292-2303. [CrossRef]

9. Gatteschi, V.; Lamberti, F.; Demartini, C.; Pranteda, C.; Santamaría, V. Blockchain and Smart Contracts for Insurance: Is the Technology Mature Enough? Future Internet 2018, 10, 20. [CrossRef]

10. Casado-Vara, R.; Prieto, J.; De la Prieta, F.; Corchado, J.M. How blockchain improves the supply chain: Case study alimentary supply chain. Procedia Comput. Sci. 2018, 134, 393-398. [CrossRef]

11. Sicari, S.; Rizzardi, A.; Grieco, L.A.; Coen-Porisini, A. Security, privacy and trust in Internet of Things: The road ahead. Comput. Netw. 2015, 76, 146-164. [CrossRef]

12. Lin, I.C.; Liao, T.C. A Survey of Blockchain Security Issues and Challenges. IJ Netw. Secur. 2017, 19, 653-659.

13. Briones, A.G.; Villaverde, D.V. Aspectos legales y riesgos emergentes en la utilización de Smart Contracts basados en Blockchain. In FODERTICS 7.0: Estudios Sobre Derecho Digital; Fundación Dialnet: La Rioja, Spain, 2019; pp. 245-252.

14. Governatori, G.; Idelberger, F.; Milosevic, Z.; Riveret, R.; Sartor, G.; Xu, X. On legal contracts, imperative and declarative smart contracts, and blockchain systems. Artif. Intell. Law 2018, 26, 377-409. [CrossRef]

15. Nikolic, I.; Kolluri, A.; Sergey, I.; Saxena, P.; Hobor, A. Finding the Greedy, Prodigal, and Suicidal Contracts at Scale. 2018. Available online: https://arxiv.org/abs/1802.06038 (accessed on 15 January 2019).

16. Giancaspro, M. Is a 'smart contract'really a smart idea? Insights from a legal perspective. Comput. Law Secur. Rev. 2017, 33, 825-835. [CrossRef]

17. Luu, L.; Chu, D.H.; Olickel, H.; Saxena, P.; Hobor, A. Making smart contracts smarter. In Proceedings of the 2016 ACM SIGSAC Conference on Computer and Communications Security, Vienna, Austria, 26-28 October 2016; pp. 254-269.

18. Atzei, N.; Bartoletti, M.; Cimoli, T. A survey of attacks on ethereum smart contracts (sok). In Principles of Security and Trust; Springer: Berlin/Heidelberg, Germany, 2017; pp. 164-186. 
19. Mengelkamp, E.; Notheisen, B.; Beer, C.; Dauer, D.; Weinhardt, C. A blockchain-based smart grid: Towards sustainable local energy markets. Comput. Sci. -Res. Dev. 2018, 33, 207-214. [CrossRef]

20. Saberi, S.; Kouhizadeh, M.; Sarkis, J.; Shen, L. Blockchain technology and its relationships to sustainable supply chain management. Int. J. Prod. Res. 2019, 57, 2117-2135. [CrossRef]

21. Casino, F.; Dasaklis, T.K.; Patsakis, C. A systematic literature review of blockchain-based applications: Current status, classification and open issues. Telemat. Inform. 2018, 36, 55-81. [CrossRef]

22. de Vries, A. Renewable Energy Will Not Solve Bitcoin's Sustainability Problem. Joule 2019, 3, $893-898$. [CrossRef]

23. Higgins, S. European Insurance Firms Launch New Blockchain Consortium. Available online: http: //www.coindesk.com/europe-insurance-blockchain-consortium/ (accessed on 11 November 2018).

24. Tian, F. An agri-food supply chain traceability system for China based on RFID \& blockchain technology. In Proceedings of the 13th IEEE International Conference on Service Systems and Service Management (ICSSSM), Kunming, China, 24-26 June 2016; pp. 1-6.

25. Truby, J. Decarbonizing Bitcoin: Law and policy choices for reducing the energy consumption of Blockchain technologies and digital currencies. Energy Res. Soc. Sci. 2018, 44, 399-410. [CrossRef]

26. Kshetri, N. 1 Blockchain's roles in meeting key supply chain management objectives. Int. J. Inf. Manag. 2018, 39, 80-89. [CrossRef]

27. Casado-Vara, R.; González-Briones, A.; Prieto, J.; Corchado, J.M. Smart contract for monitoring and control of logistics activities: Pharmaceutical utilities case study. In Proceedings of the 13th International Conference on Soft Computing Models in Industrial and Environmental Applications, Donostia-San Sebastian, Spain, 6-8 June 2018; Springer: Cham, Switzerland, 2018; pp. 509-517.

28. Galvez, J.F.; Mejuto, J.C.; Simal-Gandara, J. Future challenges on the use of blockchain for food traceability analysis. TrAC Trends Anal. Chem. 2018, 107, 222-232. [CrossRef]

29. Khezr, S.; Moniruzzaman, M.; Yassine, A.; Benlamri, R. Blockchain Technology in Healthcare: A Comprehensive Review and Directions for Future Research. Appl. Sci. 2019, 9, 1736. [CrossRef]

30. Tapscott, D.; Tapscott, A. How blockchain will change organizations. MIT Sloan Manag. Rev. 2017, 58, 10.

31. Levy, K.E. Book-smart, not street-smart: Blockchain-based smart contracts and the social workings of law. Engag. Sci. Technol. Soc. 2017, 3, 1-15. [CrossRef]

32. Gimenez, E.; Salinas, M.; Manzano-Agugliaro, F. Worldwide research on plant defense against biotic stresses as improvement for sustainable agriculture. Sustainability 2018, 10, 391. [CrossRef]

33. Salmerón-Manzano, E.; Manzano-Agugliaro, F. The Higher Education Sustainability through Virtual Laboratories: The Spanish University as Case of Study. Sustainability 2018, 10, 4040. [CrossRef]

34. Salmerón-Manzano, E.; Manzano-Agugliaro, F. Worldwide scientific production indexed by Scopus on Labour Relations. Publications 2017, 5, 25. [CrossRef]

35. Gavel, Y.; Iselid, L. Web of Science and Scopus: A journal title overlap study. Online Inf. Rev. 2008, 32, 8-21. [CrossRef]

36. Salmeron-Manzano, E.; Manzano-Agugliaro, F. The electric bicycle: Worldwide research trends. Energies 2018, 11, 1894. [CrossRef]

37. Tibaná-Herrera, G.; Fernández-Bajón, M.T.; De Moya-Anegón, F. Categorization of E-learning as an emerging discipline in the world publication system: A bibliometric study in SCOPUS. Int. J. Educ. Technol. High. Educ. 2018, 15, 21. [CrossRef]

38. Garrido-Cardenas, J.A.; Mesa-Valle, C.; Manzano-Agugliaro, F. Human parasitology worldwide research. Parasitology 2018, 145, 699-712. [CrossRef]

39. Garrido-Cardenas, J.A.; Manzano-Agugliaro, F.; Acien-Fernandez, F.G.; Molina-Grima, E. Microalgae research worldwide. Algal Res. 2018, 35, 50-60. [CrossRef]

40. Turban, E.; McElroy, D. Using smart cards in electronic commerce. In Proceedings of the IEEE Hawaii International Conference on System Sciences, Kohala Coast, HI, USA, 9 January 1998; Volume 4, pp. 62-69.

41. Van Eck, N.J.; Waltman, L. Software survey: VOSviewer, a computer program for bibliometric mapping. Scientometrics 2010, 84, 523-538. [CrossRef] [PubMed]

42. Garrido-Cardenas, J.; Manzano-Agugliaro, F.; González-Cerón, L.; Gil-Montoya, F.; Alcayde-Garcia, A.; Novas, N.; Mesa-Valle, C. The Identification of Scientific Communities and Their Approach to Worldwide Malaria Research. Int. J. Environ. Res. Public Health 2018, 15, 2703. [CrossRef] [PubMed] 
43. Chien, H.Y.; Jan, J.K.; Tseng, Y.M. An efficient and practical solution to remote authentication: Smart card. Comput. Secur. 2002, 21, 372-375. [CrossRef]

44. Szabo, N. Formalizing and Securing Relationships on Public Networks. 1997. Available online: http: //ojphi.org/ojs/index.php/fm/article/view/548/469 (accessed on 15 January 2019).

45. Udokwu, C.; Kormiltsyn, A.; Thangalimodzi, K.; Norta, A. The State of the Art for Blockchain-Enabled Smart-Contract Applications in the Organization. In Proceedings of the 2018 2nd International Conference on Communication and Network Technology, Chandigarh, India, 29-30 March 2018.

(C) 2019 by the authors. Licensee MDPI, Basel, Switzerland. This article is an open access article distributed under the terms and conditions of the Creative Commons Attribution (CC BY) license (http://creativecommons.org/licenses/by/4.0/). 